\title{
The Influence of Airflow Via High-Flow Nasal Cannula on Duration of Laryngeal Vestibule Closure
}

\author{
Katie Allen ${ }^{1}\left[\right.$ Kristine Galek ${ }^{1}$ (1)
}

Received: 22 May 2020 / Accepted: 21 September 2020 / Published online: 1 October 2020

(c) Springer Science+Business Media, LLC, part of Springer Nature 2020

\begin{abstract}
The purpose of this experimental study was to investigate the influence of airflow via high-flow nasal cannula (HFNC) on the duration of laryngeal vestibule closure (dLVC) and Penetration-Aspiration Scale (PAS) scores. Twenty-nine healthy adults participated in a repeated-measures design. Each participant completed a videofluoroscopic swallow study while receiving airflow via HFNC across a control condition of zero flow and conditions of 10, 20, 30, 40, 50, and $60 \mathrm{~L} / \mathrm{min}$. Five raters rated dLVC and PAS scores. Laryngeal vestibule closure was complete on all swallows. Linear regression revealed that the amount of airflow via HFNC significantly influenced dLVC, $F(1,810)=19.056, p<.001$. The mode of airway invasion for each airflow condition was PAS 2, with $>80 \%$ frequency compared to other PAS scores. Aspiration (PAS 7 or 8 ) did not occur. A Fisher's Exact test determined there was no association between normal/abnormal PAS score and no airflow/HFNC $(p=.610)$. Findings indicate that for healthy adults, airflow via HFNC influenced dLVC in a dose-dependent manner with no change in airway invasion. The influence of HFNC on dLVC was a positive relationship, meaning when airflow increased, dLVC increased, and when airflow decreased, dLVC decreased. Modulation of dLVC in response to the amount of airflow highlights the ability of healthy adults to adapt to swallow conditions as needed to protect the airway.
\end{abstract}

Keywords Swallow $\cdot$ Laryngeal vestibule closure $\cdot$ High-flow nasal cannula $\cdot$ Airway invasion

\section{Introduction}

The number of hospitalizations associated with respiratory failure has steadily increased in the USA [1] and will likely escalate exponentially, considering the recent COVID-19 pandemic. In a 2009 survey, respiratory failure resulted in 380,000 deaths and over $\$ 54$ billion in costs [1]. Severe respiratory failure requires mechanical ventilation to assist with gas exchange and reduce the work of breathing for patients. Mechanical ventilation works by blowing positive air pressure into the lungs, which stents the airway open [2-5]. There are invasive and non-invasive types of mechanical ventilation. Invasive ventilation requires placement of a tracheostomy or endotracheal tube. Non-invasive ventilation utilizes a facial mask or high-flow nasal cannula. Compared

Katie Allen

2katieallen@gmail.com

Kristine Galek

Kgalek@med.unr.edu

1 University of Nevada, 1664 North Virginia Street, Mailstop 0152, Reno, NV 89557, USA to invasive ventilation, non-invasive ventilation is associated with fewer infections, fewer prescribed antibiotics, lower mortality, and shorter stays in the intensive care unit $[6,7]$. Non-invasive ventilation delivered using a high-flow nasal cannula (HFNC) is a more recent development [8]. HFNC provides precise adjustment of airflow up to $60 \mathrm{~L} / \mathrm{min}$ [2]. Additionally, patients tolerate HFNC to a greater degree than the facial mask [2]. HFNC is now routinely used in hospitals due to positive respiratory outcomes [9-14].

There is concern that the positive pressure at work to stent the airway open during HFNC may cause unwanted complications during eating and swallowing. During swallowing, the airway must close briefly to prevent material from entering the airway (i.e., penetration, aspiration). Laryngeal vestibule closure is the primary means of airway protection [15]. Laryngeal vestibule closure acts as an umbrella, safely directing material (food/liquid/saliva) into the digestive tract while keeping the airway covered. The mean duration of laryngeal vestibule closure (dLVC) for healthy adults is between 310 and $1070 \mathrm{~ms}$ [16] depending on the swallow condition (e.g., bolus consistency or volume). $\mathrm{dLVC}$ can be measured using videofluoroscopy (X-ray 
video) and may be sensitive to capture kinematic changes to swallowing in response to swallow conditions [15]. Delayed, short, or absent laryngeal vestibule closure is associated with increased penetration or aspiration [17-25]. Therefore, dLVC is a vital measure to investigate during HFNC use.

Multiple actions are required to achieve laryngeal vestibule closure. First, there is hyolaryngeal complex (hyoid and larynx) movement anteriorly and superiorly. Hyolaryngeal excursion forward is due to contraction of the submental muscles. Upward movement occurs as pharyngeal constrictor muscles shorten. Hyolaryngeal excursion positions the epiglottis superiorly and anteriorly against the base of tongue, with the superior portion of the epiglottis free. Hyolaryngeal excursion narrows the laryngeal vestibule while simultaneously widening the pharynx for bolus passage.

The second action of laryngeal vestibule closure is arytenoid movement. During swallowing, the arytenoids adduct and pivot anteriorly. Adductor muscles include the lateral cricoarytenoids, with some contribution of the transverse and oblique arytenoids as well as the thyroarytenoid. Anterior tilting of the arytenoids is accomplished by contraction of the lateral cricoarytenoids and aryepiglottic muscle [26]. Anterior tilting of the arytenoids accounts for one-half to one-third of closure [26].

The third action of laryngeal vestibule closure is aryepiglottic fold movement [27, 28]. The aryepiglottic folds make up the lateral walls of the laryngeal vestibule. At rest, the aryepiglottic folds are upright partially due to their attachment to the upright epiglottis. Fibers of the oblique arytenoid muscle travel along the quadrangular membrane in the aryepiglottic folds as the aryepiglottic muscle [29]. When the aryepiglottic muscle contracts during swallowing, the inlet of the laryngeal vestibule is closed by narrowing of the aryepiglottic folds [28]. When the aryepiglottic folds are drawn during swallowing, the bolus is directed laterally around the airway.

The fourth action of laryngeal vestibule closure is epiglottic inversion. When the hyolaryngeal complex moves anteriorly and superiorly, the base of the epiglottis is positioned closer to the base of tongue, which also tilts the epiglottis horizontally. The base of tongue pushes the epiglottis posteriorly and inferiorly $[15,30]$. This inverts the free end of the epiglottis downward and backward over the laryngeal vestibule. Thus, the epiglottis inverts/folds over the arytenoids providing further closure of the laryngeal vestibule [31].

Laryngeal vestibule closure can be identified on fluoroscopy when the arytenoids contact the base of epiglottis and the epiglottis inverts over the base of the arytenoids [26].

Previous investigations on the influence of HFNC use during swallowing are limited in both healthy and patient populations. Most studies did not control for concomitant disease or injury [32-34]. Therefore, it is unclear if any changes to swallow function were due to HFNC, disease, or both [32-34]. Of those that used healthy subjects to control for disease, most reviewed peripheral measures of swallowing such as swallow frequency and swallowing-breathing patterns [35-38]. Previous investigations offer conflicting results: some studies indicate no impact of HFNC on swallowing [34, 37], others say HFNC may improve swallowing $[37,38]$, and others that HFNC may worsen swallowing [33, 36, 39]. Most importantly, no study to date has systematically investigated the impact of HFNC dosage on laryngeal vestibule closure timing.

Therefore, this study aimed to: (1) investigate the influence of airflow delivered via HFNC on the duration of laryngeal vestibule closure; and (2) describe airway invasion during airflow delivered via HFNC. We hypothesized that airflow via HFNC would decrease dLVC and increase airway invasion.

\section{Methods}

\section{Participants}

The sample size was estimated a priori using G*Power 2 [40], suggesting a minimum of 17 participants for a type I error rate of 0.05 and a power of 0.80 . The University Institutional Review Board approved this study. Posted advertisements recruited adult participants from university medical clinics and classrooms. Any healthy adults were eligible for the study. Exclusion criteria included any history of respiratory disease, neurologic deficits, dysphagia or difficulty swallowing, and current pregnancy. All participants provided informed consent prior to data collection.

\section{Instrumentation}

Each participant was fit with an Optiflow ${ }^{\mathrm{TM}}+$ high-flow nasal cannula (Auckland, New Zealand: Fisher \& Paykel). The AIRVO ${ }^{\text {TM }} 2$ system provided humidified airflow (Auckland, New Zealand: Fisher \& Paykel). The AIRVO ${ }^{\text {TM }} 2$ system had three adjustable settings: temperature, airflow, and supplemental oxygenation. The device temperature was $37^{\circ} \mathrm{C}$. Oxygenation was $0.21 \mathrm{FiO}_{2}$ (room air). There was no supplemental oxygenation because this research focused on the effect of airflow on swallowing and not oxygenation concentration. AIRVO ${ }^{\mathrm{TM}} 2$ provides airflow from 2 to 60 $\mathrm{L} / \mathrm{min}$ (LPM). Detaching the distal end of the nasal cannula tubing from the device achieved a control condition of zero airflow. Airflow conditions of 10, 20, 30, 40, 50, and $60 \mathrm{LPM}$ were selected to represent an adequate sample of available high-flow rates.

Completed videofluoroscopic swallow studies (VFSS) used the GE OEC Model 9800 Plus C-arm videofluoroscopy 
system (Chicago, IL: GE Healthcare). Recordings occurred at the rate of 30 images per second in the lateral viewing plane using the Digital Swallowing Workstation (Lincoln Park, NJ: Kay Pentax). Images were collimated to include the participant's oral cavity anteriorly, cervical spine posteriorly, the floor of the nasal cavity superiorly, and the upper esophagus and trachea inferiorly.

During VFSS, each participant swallowed liquid boluses of forty percent weight/volume Varibar Barium Sulfate Suspension $^{\mathrm{TM}}$ (Bracco Imaging) across multiple airflow conditions. A thin liquid was selected as it may require the most optimal swallow timing in healthy subjects [41] and, therefore, may have been the most sensitive to change. A $20 \mathrm{ml}$ bolus volume was used for all treatment conditions to control for timing changes related to volume and is an expected sip size [42-45]. First, swallows of $1 \mathrm{ml}$ with no airflow via HFNC mask were collected for a baseline hold position [46] and to allow participants to adjust to the barium. Participants then swallowed $20 \mathrm{ml}$ boluses using the following airflow conditions: 0 LPM (control condition), 10 LPM, 20 LPM, 30 LPM, 40 LPM, 50 LPM, 60 LPM. The sequence of delivered airflow conditions was counterbalanced across participants using a random generator program to guard against order effects. Participants were blind to airflow conditions to the best extent possible.

A video slideshow with audio narration of instructions was played during data collection to standardize procedures. During each airflow condition, participants were told to "put the entire contents of the cup in your mouth and hold it until told to swallow." A research assistant ensured that the participant put all of the barium in their mouth and that the cup was empty. Next, the participant was told to "swallow the contents of the cup in one swallow." Videofluoroscopy was turned on by the radiology technologist at that point to capture the swallow. The technologist turned off fluoroscopy as soon as the barium bolus passed out of view for each swallow. The same procedures repeated for swallows across all airflow conditions.

\section{Outcome Measures}

Five raters (two experienced speech pathologists and three novice undergraduate students) reviewed all de-identified swallow videos to determine dLVC and Penetration-Aspiration Scale (PAS) scores for airway invasion [47]. Raters re-rated twenty percent of videos to determine intrarater reliability. Raters were blind to participants and airflow conditions. Raters completed pre-experimental training to improve reliability $[16,48,49]$, which included how to measure dLVC and PAS scores using frame-by-frame analysis in Swallowtail software (Arlington Heights, IL: Belldev Medical). Raters were instructed to score the first swallow if multiple swallows occurred per bolus.
dLVC was defined as the time between the first frame of complete laryngeal vestibule closure and the first frame of laryngeal vestibule re-opening $[16,19,50]$. Raters advanced videos in Swallowtail until the first frame of laryngeal vestibule closure was visible on the left side of the screen to measure dLVC. No airspace or contrast seen in the laryngeal structures indicated complete laryngeal vestibule closure [15]. Incomplete laryngeal vestibule closure would be indicated by a dLVC of zero. Raters then advanced the video on the right side of the screen to the first frame of laryngeal re-opening. Swallowtail automatically calculated the time between the left and right frames to produce dLVC. Raters determined Penetration-Aspiration Scale scores for every swallow [47, 51].

\section{Statistical Analysis}

Statistical analyses were conducted using IBM SPSS Statistics for Windows, versions 25 and 26 (Armonk, NY: IBM Corp.). All five raters rated each swallow. Twenty percent of videos were chosen at random and repeated by each rater 1 week following initial completion to conduct intrarater reliability. For dLVC reliability, a mean-rating $(k=5)$, consistency-agreement, two-way random-effects model calculated intraclass coefficient (ICC) estimates and their 95\% confidence intervals. ICC was considered "excellent" if $\geq 0.90$, "good" if between 0.75 and 0.90 , "moderate" if between 0.50 and 0.75 , and "poor" if $<0.50$ [52]. For PAS scores, percent agreement calculated interrater and intrarater agreement. Linear regression estimates determined the influence of airflow via HFNC on dLVC. A prediction equation indicated the amount and direction of change in the dLVC for every unit of airflow. Frequency counts and the mode determined the frequency of PAS scores for each airflow condition. A contingency table with Fisher's Exact test was used to determine any association between PAS scores and flow using the categories of normal PAS score versus abnormal PAS score and no airflow (0 LPM) and HFNC (>0 LPM).

\section{Results}

Forty younger adults (less than 60 years of age) met inclusion criteria and denied any history of respiratory disease, neurologic deficits, dysphagia or difficulty swallowing, and current pregnancy. All participants completed the study with no adverse effects. A recording error removed eleven cases from the dataset. Therefore, the final analysis included 29 participants ( 23 females, 6 males). A total of 812 swallows were rated (swallows from 29 participants across seven airflow conditions by four raters). Laryngeal vestibule closure was determined to be complete on all swallows. 
Table 1 Intrarater reliability for dLVC

\begin{tabular}{|c|c|c|c|c|c|c|c|}
\hline \multirow[t]{2}{*}{ Rater } & \multirow[t]{2}{*}{ Measure } & \multicolumn{2}{|c|}{$95 \%$ confidence interval } & \multicolumn{4}{|c|}{$F$ test with true value 0} \\
\hline & & Lower bound & Upper bound & Value & $d f 1$ & $d f 2$ & Sig \\
\hline 1 & $\mathrm{ICC}=.963$ & .931 & .980 & 27.142 & 41 & 41 & .000 \\
\hline 2 & $\mathrm{ICC}=.981$ & .965 & .990 & 52.669 & 41 & 41 & .000 \\
\hline 3 & $\mathrm{ICC}=.991$ & .984 & .995 & 115.786 & 41 & 41 & .000 \\
\hline 4 & $\mathrm{ICC}=.996$ & .992 & .998 & 238.079 & 41 & 41 & .000 \\
\hline 5 & $\mathrm{ICC}=.649$ & .348 & .811 & 2.852 & 41 & 41 & .001 \\
\hline
\end{tabular}

$d L V C$ duration of laryngeal vestibule closure
Table 2 Interrater reliability for PAS scores

\section{Reliability}

For dLVC, intrarater reliability was excellent for all raters except for one who had only moderate reliability (Table 1). An Intrarater ICC of 0.80 or higher was deemed acceptable [53], resulting in four out of five rater's data retained for analysis. Interrater reliability was excellent for these raters $(\mathrm{ICC}=0.975$ with $95 \%$ confidence interval $=0.968-0.980)$. For PAS scores, intrarater agreement was $90 \%$ or greater for all raters (Table 2). The interrater agreement for PAS was $22 \%$.

\begin{tabular}{ll}
\hline Rater & $\begin{array}{l}\text { Percent } \\
\text { agree- } \\
\text { ment }\end{array}$ \\
\hline 1 & $90 \%$ \\
2 & $100 \%$ \\
3 & $98 \%$ \\
4 & $100 \%$ \\
5 & $91 \%$ \\
\hline$P A S$ & Penetration-Aspiration \\
Scale &
\end{tabular}

\section{Aim 1: Determine the Influence of Airflow Delivered Via HFNC on dLVC}

Data screening found no outliers nor statistical assumption violations. Descriptive statistics for dLVC are in Table 3. Linear regression revealed that the amount of airflow via HFNC significantly influenced dLVC, $F(1$, $810)=19.056, p<0.001$. The relationship was positive, meaning when airflow increased, dLVC also increased. The regression equation was: $\mathrm{dLVC}=0.334+0.002$ (airflow). Or, for every unit increase of airflow, dLVC increased by $0.002 \mathrm{~s}$.

\section{Aim 2: Describe Airway Invasion During Airflow Via HFNC}

The frequency counts of PAS scores for each airflow condition are in Table 4. The mode for each airflow condition was PAS 2, with $>80 \%$ frequency compared to other scores. In the entire dataset, scores of one, two, and four comprised 99.2\% of total swallows. These scores are considered normal during swallowing, whereas PAS 3, 7, and 8 are considered abnormal [54]. PAS 3 occurred in $0.2 \%$ of swallows, and aspiration (PAS 7 or 8 ) did not occur ( $0 \%$ of swallows). The overall frequency of PAS scores is similar to those reported in previous literature for normal swallowing in adults [41, 51,55]. A Fisher's Exact test was conducted to determine the

Table 3 Means and standard deviations of dLVC across flow conditions

\begin{tabular}{llll}
\hline Condition $(\mathrm{LPM})^{\mathrm{a}}$ & $M(\mathrm{SD})$ & \multicolumn{2}{l}{$95 \%$ confidence interval } \\
\cline { 3 - 4 } & & Lower bound & Upper bound \\
\hline 0 & $.358(.253)$ & .311 & .404 \\
10 & $.364(.231)$ & .322 & .407 \\
20 & $.356(.209)$ & .317 & .394 \\
30 & $.380(.267)$ & .331 & .430 \\
40 & $.388(.223)$ & .347 & .429 \\
50 & $.447(.334)$ & .386 & .509 \\
60 & $.491(.385)$ & .420 & .561 \\
\hline
\end{tabular}

$d L V C$ duration of laryngeal vestibule closure, $L P M$ liters per minute

${ }^{\mathrm{a}} n=116$ 
Table 4 Frequencies of PAS scores per airflow condition

\begin{tabular}{lrrrrrrr}
\hline & 0 LPM & 10 LPM & 20 LPM & 30 LPM & 40 LPM & 50 LPM & 60 LPM \\
\hline PAS 1 & 24 & 24 & 19 & 25 & 22 & 19 & 21 \\
PAS 2 & 121 & 118 & 124 & 120 & 121 & 125 & 122 \\
PAS 3 & 0 & 2 & 1 & 0 & 2 & 1 & 2 \\
PAS 4 & 0 & 1 & 1 & 0 & 0 & 0 & 0 \\
PAS 5 & 0 & 0 & 0 & 0 & 0 & 0 & 0 \\
PAS 6 & 0 & 0 & 0 & 0 & 0 & 0 & 0 \\
PAS 7 & 0 & 0 & 0 & 0 & 0 & 0 & 0 \\
PAS 8 & 0 & 0 & 0 & 0 & 0 & 0 & 0 \\
\hline
\end{tabular}

PAS Penetration-Aspiration Scale, $L P M$ liters per minute association between PAS score and airflow. No statistically significant association was found, $p=0.610$. Thus, change in airflow via HFNC was not associated with a change in airway invasion in healthy adults.

\section{Discussion}

This study investigated the influence of airflow via high-flow nasal cannula (HFNC) on the duration of laryngeal vestibule closure (dLVC) and airway invasion in healthy adults. Results indicated that laryngeal vestibule closure was complete on all swallows and that airflow via HFNC did not stent the airway open during swallowing for healthy adults. PAS scores were virtually unchanged across airflow conditions, with a mode of PAS 2. However, airflow via HFNC did significantly change dLVC. The influence of HFNC on dLVC was a positive relationship, meaning when airflow increased, dLVC increased, and when airflow decreased, dLVC decreased.

The positive relationship between HFNC and dLVC is similar to previous research on varying liquid bolus volumes. Smaller bolus volumes are associated with shorter dLVC, whereas larger bolus volumes have longer dLVC [26, 50, 56-60]. The adaptation of dLVC may help to protect the airway, as aspiration is uncommon in healthy adults despite changes in bolus volume. Adaptation refers to a change in swallowing to be better suited for the swallow conditions $[61,62]$. Change in dLVC in response to bolus volumes, therefore, does not demonstrate impairment, but normal flexibility in healthy individuals. We postulate that the modulation of dLVC in response to the amount of airflow highlights the ability of healthy adults to adapt to swallow conditions as needed to protect the airway.

Although study participants were able to adapt dLVC according to the amount of airflow, the highest airflow rates via HFNC resulted in less predictable durations of closure. Confidence intervals are wider at 50 and 60 LPM, indicating greater variability at these higher levels (Table 3). Additionally, some participants reported increased difficulty with swallowing at higher airflow rates. This phenomenon is similar to previous literature that showed an airflow rate of $>40$ LPM resulted in aspiration, choking or patients reporting increased difficulty of swallowing [33, 39]. Similarly, it is higher airflow rates ( $>35$ LPM) believed to stent the airway open during use by mimicking a continuous positive airway pressure (CPAP) effect [2, 63, 64]. Greater variability in $\mathrm{dLVC}$ at higher airflow levels may be evidence for increased difficulty with trying to maintain closure. Many participants in this study subjectively perceived difficulty swallowing during the highest airflow conditions. Although participants were blind to airflow conditions, many reported that they had "trouble swallowing" during what they perceived was higher airflow. Similarly, in a previous study, participants reported difficulty swallowing at 40 and 50 LPM [39].

This study highlights the importance for clinicians to examine swallow kinematics during HFNC use, not just penetration and aspiration. Penetration and aspiration have been the focus of previous investigations of swallowing during HFNC use [32-34]. This narrow focus does not necessarily aid in understanding physiologic processes. For example, PAS scores were unchanged despite the influence of HFNC use. In contrast, dLVC timing measures were sensitive to capture significant changes across airflow conditions.

Results from this study indicate that airflow via HFNC influences dLVC in a dose-dependent manner in healthy adults. It is not clear, however, if this would be validated in patient populations. For example, literature shows that adults poststroke with impaired laryngeal vestibule closure consequently demonstrate worse airway protection [23, 65]. Future research is needed to determine how airflow via HFNC might influence dLVC in patients with already impaired laryngeal vestibule closure.

This study was not without limitations. Results were limited to healthy young adults and may not be generalizable to older adults who are known to exhibit longer durations of swallowing [59]. The sample was mostly female, and so further investigation should be considered for sex or body size differences. Although PAS intrarater reliability was acceptable enough to retain data from all raters, the final 
interrater reliability was quite low. Upon further investigation, the novice raters had better agreement (99\%) than experienced raters (23\%), which dramatically lowered PAS interrater reliability.

\section{Conclusions}

In healthy young adults, airflow via HFNC influenced dLVC in a dose-dependent manner. The influence of HFNC on dLVC demonstrated a positive relationship, meaning dLVC increased when airflow increased and vice versa. At very high-flow levels (50 and 60 LPM), the healthy adults in this study had greater variability of dLVC. Airway invasion was essentially unchanged across airflow conditions, with a mode of PAS 2 for all airflow levels. Modulation of dLVC in response to the amount of airflow highlights the ability of healthy adults to adapt to swallow conditions as needed to protect the airway. Future research is warranted in both healthy and patient populations.

Acknowledgements We would like to offer our thanks for the research assistants and raters who invested their time in this project.

Funding This study was funded by University of Nevada, Reno, School of Medicine Faculty Development Grant.

\section{Compliance with Ethical Standards}

Conflict of interest Authors Katie Allen and Kristine E. Galek declare that they have no conflicts of interest.

Ethical approval All procedures performed in studies involving human participants were in accordance with the ethical standards of the Institutional Review Board of the University of Nevada, Reno. All participants provided informed consent prior to data collection and completed the study with no adverse effects.

\section{References}

1. Stefan MS, Shieh M-S, Pekow PS, Rothberg MB, Steingrub JS, Lagu T, Lindenauer PK. Epidemiology and outcomes of acute respiratory failure in the United States, 2001 to 2009: a national survey. J Hosp Med. 2013;8:76-82.

2. Ward JJ. High-flow oxygen administration by nasal cannula for adult and perinatal patients. Respir Care. 2013;58:98-122.

3. Wilkinson D, Andersen C, O'Donnell CP, Paoli AGD. High flow nasal cannula for respiratory support in preterm infants. Cochrane Database Syst Rev. 2016. https://doi.org/10.1002/14651858. CD006405.pub3.

4. Ferrara L, Bidiwala A, Sher I, Pirzada M, Barlev D, Islam S, Rosenfeld W, Crowley CC, Hanna N. Effect of nasal continuous positive airway pressure on the pharyngeal swallow in neonates. J Perinatol. 2017;37:398.

5. Gay PC. Complications of non-invasive ventilation in acute care. Respiratory Care. 2009;54:246.
6. Brochard L. Mechanical ventilation: invasive versus noninvasive. Eur Respir J. 2003;22:31s-7s.

7. Girou E, Schortgen F, Delclaux C, Brun-Buisson C, Blot F, Lefort Y, Lemaire F, Brochard L. Association of non-invasive ventilation with nosocomial infections and survival in critically ill patients. JAMA. 2000;284:2361-7.

8. Tiruvoipati R, Lewis D, Haji K, Botha J. High-flow nasal oxygen vs high-flow face mask: a randomized crossover trial in extubated patients. J Crit Care. 2010;25:463-8.

9. Dodrill P, Gosa M, Thoyre S, Shaker C, Pados B, Park J, DePalma N, Hirst K, Larson K, Perez J, Hernandez K. FIRST, DO NO HARM: a response to "oral alimentation in neonatal and adult populations requiring high-flow oxygen via nasal cannula”. Dysphagia. 2016;31:781-2.

10. Hanin M, Nuthakki S, Malkar MB, Jadcherla SR. Safety and efficacy of oral feeding in infants with BPD on nasal CPAP. Dysphagia. 2015;30:121-7.

11. Kadivar M, Mosayebi Z, Razi N, Nariman S, Sangsari R. High flow nasal cannulae versus nasal continuous positive airway pressure in neonates with respiratory distress syndrome managed with insure method: a randomized clinical trial. Iran J Med Sci. 2016;41:494-500.

12. Kernick J, Magarey J. What is the evidence for the use of high flow nasal cannula oxygen in adult patients admitted to critical care units? A systematic review. Aust Crit Care. 2010;23:53-70.

13. Liesching TN, Lei Y. Efficacy of high-flow nasal cannula therapy in intensive care units. J Intensive Care Med. 2016;34:140-52.

14. Ambrosino N, Vagheggini G. Non-invasive positive pressure ventilation in the acute care setting: where are we? Eur Respir J. 2008;31:874-86.

15. Vose A, Humbert IA. "Hidden in plain sight": a descriptive review of laryngeal vestibule closure. Dysphagia. 2018. https:// doi.org/10.1007/s00455-018-9928-1.

16. Molfenter SM, Steele CM. Temporal variability in the deglutition literature. Dysphagia. 2012;27:162-77.

17. Kim YH, Han TR, Nam HS, Seo HG, Oh B-M. Temporal characteristics of laryngeal penetration and aspiration in stroke patients. NeuroRehabilitation. 2019;44:231-8.

18. Leonard R. Predicting aspiration risk in patients with dysphagia: Evidence from fluoroscopy. Laryngoscope Investig Otolaryngol. 2019;4:83-8.

19. Molfenter SM, Steele CM. Kinematic and temporal factors associated with penetration-aspiration in swallowing liquids. Dysphagia. 2014;29:269-76.

20. Kahrilas PJ, Lin S, Rademaker AW, Logemann JA. Impaired deglutitive airway protection: a videofluoroscopic analysis of severity and mechanism. Gastroenterology. 1997;113:1457-64.

21. Nativ-Zeltzer N, Logemann JA, Kahrilas PJ. Comparison of timing abnormalities leading to penetration versus aspiration during the oropharyngeal swallow. Laryngoscope. 2014;124:935-41.

22. Perlman AL, Booth BM, Grayhack JP. Videofluoroscopic predictors of aspiration in patients with oropharyngeal dysphagia. Dysphagia. 1994;9:90-5.

23. Power ML, Hamdy S, Singh S, Tyrrell PJ, Turnbull I, Thompson DG. Deglutitive laryngeal closure in stroke patients. J Neurol Neurosurg Psychiatry. 2007;78:141-6.

24. Power ML, Hamdy S, Goulermas JY, Tyrrell PJ, Turnbull I, Thompson DG. Predicting aspiration after hemispheric stroke from timing measures of oropharyngeal bolus flow and laryngeal closure. Dysphagia. 2009;24:257-64.

25. Steele CM, Cichero J. Physiological factors related to aspiration risk: a systematic review. Dysphagia. 2014;29:295-304.

26. Logemann JA, Kahrilas PJ, Cheng J, Pauloski BR, Gibbons PJ, Rademaker AW, Lin S. Closure mechanisms of laryngeal vestibule during swallow. Am J Physiol. 1992;262:G338-344. 
27. Ekberg O, Sigurjónsson SV. Movement of the epiglottis during deglutition. Gastrointest Radiol. 1982;7:101-7.

28. Ekberg O. Closure of the laryngeal vestibule during deglutition. Acta Otolaryngol. 1982;93:123-9.

29. Andaloro C, La Mantia I. Anatomy, Head and Neck, Larynx Arytenoid Cartilage. StatPearls. Treasure Island: StatPearls Publishing; 2019.

30. Pearson WG, Taylor BK, Blair J, Martin-Harris B. Computational analysis of swallowing mechanics underlying impaired epiglottic inversion. Laryngoscope. 2016;126:1854-8.

31. Dodds W, Stewart E, Logemann J. Physiology and radiology of the normal oral and pharyngeal phases of swallowing. Am J Roentgenol. 1990;154:953-63.

32. Jose-Flores M, Eng K, Gerrity E, Sinha N. Initiation of oral intake in patients using high-flow nasal cannula: a retrospective analysis. Perspect ASHA Spec Interest Groups. 2019;4:522-31.

33. Jaffe A, Seevaratnam A, Waters S. Risk of aspiration in patients on high-flow oxygen therapy. In: C52. Critical care case reports: good vibrations - mechanical ventilation from NIV to ECMO. American Thoracic Society; 2018. p. A5281. https://www.atsjournal s.org/doi/abs/10.1164/ajrccm-conference.2018.197.1_MeetingAbs tracts.A5281.

34. Leder SB, Siner JM, Bizzarro MJ, McGinley BM, Lefton-Greif MA. Oral alimentation in neonatal and adult populations requiring highflow oxygen via nasal cannula. Dysphagia. 2016;31:154-9.

35. Samson N, St-Hilaire M, Nsegbe E, Reix P, Moreau-Bussiere F, Praud JP. Effect of nasal continuous or intermittent positive airway pressure on nonnutritive swallowing in the newborn lamb. J Appl Physiol (Bethesda, Md: 1985). 2005;99:1636-42.

36. Nishino T, Sugimori K, Kohchi A, Hiraga K. Nasal constant positive airway pressure inhibits the swallowing reflex. Am Rev Respir Dis. 1989;140:1290-3.

37. Sanuki T, Mishima G, Kiriishi K, Watanabe T, Okayasu I, Kawai M, Kurata S, Ayuse T. Effect of nasal high-flow oxygen therapy on the swallowing reflex: an in vivo volunteer study. Clin Oral Invest. 2017;21:915-20.

38. Garguilo M, Lejaille M, Vaugier I, Orlikowski D, Terzi N, Lofaso $\mathrm{F}$, Prigent $\mathrm{H}$. Non-invasive mechanical ventilation improves breathing-swallowing interaction of ventilator dependent neuromuscular patients: a prospective crossover study. PLoS ONE. 2016;11:e0148673.

39. Oomagari M, Fujishima I, Katagiri N, Arizono S, Watanabe K, Ohno T, Maeda H, Moriwaki M, Fujimori M, Ohgi S. Swallowing function during high-flow nasal cannula therapy. Eur Respir J. 2015. https://doi.org/10.1183/13993003.congress-2015.pa4199.

40. Faul F, Erdfelder E, Lang A, Buchner A. G*Power 3: a flexible statistical power analysis program for the social, behavioral, and biomedical sciences. Behav Res Methods. 2007;39:175-91.

41. Humbert IA, Sunday KL, Karagiorgos E, Vose AK, Gould F, Greene L, Tolar A, Rivet A. Swallowing kinematic differences across frozen, mixed, and ultrathin liquid boluses in healthy adults: age, sex, and normal variability. J Speech Lang Hear Res. 2018;61:1544-59.

42. Bennett JW, Van Lieshout PHHM, Pelletier CA, Steele CM. Sip-sizing behaviors in natural drinking conditions compared to instructed experimental conditions. Dysphagia. 2009;24:152-8.

43. Adnerhill I, Ekberg O, Groher ME. Determining normal bolus size for thin liquids. Dysphagia. 1989;4:1-3.

44. Lawless HT, Bender S, Oman C, Pelletier C. Gender, age, vessel size, cup vs. straw sipping, and sequence effects on sip volume. Dysphagia. 2003;18:196-202.

45. Nilsson H, Ekberg O, Olsson R, Kjellin O, Hindfelt B. Quantitative assessment of swallowing in healthy adults. Dysphagia. 1996;11:110-6.

46. Leonard R, Kendall KA. Dysphagia assessment and treatment planning. 4th ed. San Diego: Plural Publishing; 2019.
47. Rosenbek JC, Robbins J, Roecker EB, Coyle JL, Wood JL. A penetration-aspiration scale. Dysphagia. 1996;11:93-8.

48. Baijens L, Barikroo A, Pilz W. Intrarater and interrater reliability for measurements in videofluoroscopy of swallowing. Eur J Radiol. 2013;82:1683-95.

49. Nordin NA, Miles A, Allen JJD. Measuring competency development in objective evaluation of videofluoroscopic swallowing studies. Dysphagia. 2017;32:427-36.

50. Molfenter SM, Steele CM. Variation in temporal measures of swallowing: sex and volume effects. Dysphagia. 2013;28:226-33.

51. Robbins J, Coyle JL, Rosenbek JC, Roecker E, Wood J. Differentiation of normal and abnormal airway protection during swallowing using the Penetration-Aspiration Scale. Dysphagia. 1999;14:228-32.

52. Koo TK, Li MY. A guideline of selecting and reporting intraclass correlation coefficients for reliability research. J Chiropr Med. 2016;15:155-63.

53. Stoeckli SJ, Huisman TAGM, Seifert BAGM, Martin-Harris BJW. Interrater reliability of videofluoroscopic swallow evaluation. Dysphagia. 2003;18:53-7.

54. Steele CM, Grace-Martin K. Reflections on clinical and statistical use of the Penetration-Aspiration Scale. Dysphagia. 2017;32:601-16.

55. Allen JE, White CJ, Leonard RJ, Belafsky PC. Prevalence of penetration and aspiration on videofluoroscopy in normal individuals without dysphagia. Otolaryngol Head Neck Surg. 2010;142:208-13.

56. Logemann JA, Pauloski BR, Rademaker AW, Colangelo LA, Kahrilas PJ, Smith $\mathrm{CH}$. Temporal and biomechanical characteristics of oropharyngeal swallow in younger and older men. J Speech Lang Hear Res: JSLHR. 2000;43:1264-74.

57. Logemann JA, Pauloski BR, Rademaker AW, Kahrilas PJ. Oropharyngeal swallow in younger and older women: videofluoroscopic analysis. J Speech Lang Hear Res. 2002;45:434-45.

58. Hiss SG, Strauss M, Treole K, Stuart A, Boutilier S. Swallowing apnea as a function of airway closure. Dysphagia. 2003;18:293-300.

59. Kendall KA, McKenzie S, Leonard RJ, Gonçalves MI, Walker A. Timing of events in normal swallowing: a videofluoroscopic study. Dysphagia. 2000;15:74-83.

60. Hoffman MR, Ciucci MR, Mielens JD, Jiang JJ, McCulloch TM. Pharyngeal swallow adaptations to bolus volume measured with high resolution manometry. Laryngoscope. 2010;120:2367-73.

61. Humbert IA, German RZ. New directions for understanding neural control in swallowing: the potential and promise of motor learning. Dysphagia. 2013;28:1-10.

62. Humbert IA, Lokhande A, Christopherson H, German R, Stone A. Adaptation of swallowing hyo-laryngeal kinematics is distinct in oral vs. pharyngeal sensory processing. J Appl Physiol. 2012;112:1698-705.

63. Parke RL, McGuinness S, Eccleston M. Nasal high-flow therapy delivers low level positive airway pressure. BJA: Br J Anaesth. 2009; 103:886-90.

64. Groves N, Tobin A. High flow nasal oxygen generates positive airway pressure in adult volunteers. Aust Crit Care. 2007;20:126-31.

65. Park T, Kim Y, Ko D-H, McCullough GH. Initiation and duration of laryngeal closure during the pharyngeal swallow in post-stroke patients. Dysphagia. 2010;25:177-82.

Publisher's Note Springer Nature remains neutral with regard to jurisdictional claims in published maps and institutional affiliations.

\section{Katie Allen $\mathrm{PhD}$ CCC-SLP}

\section{Kristine Galek PhD CCC-SLP}

